\title{
Avaliação da anomalia da gravidade na região do barramento da Usina Hidroelétrica de Mauá
}

Gravity Anomaly Evaluation in the Dam Region of Hydroelectric Plant of Mauá

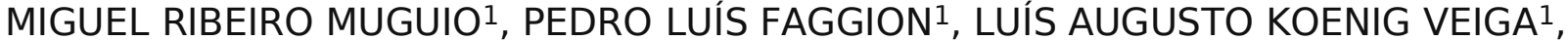 \\ CARLOS AURÉLIO NADAL ${ }^{1}$, WANDER A DA CRUZ1, MARCOS ALBERTO SOARES², \\ ISABELLA F. REBUTINI FIGUEIRA ${ }^{3}$
}

\author{
1Universidade Federal do Paraná - UFPR, Paraná, ${ }^{2}$ Copel Geração e Transmissão, ${ }^{3}$ Institutos Lactec- \\ mmuguio@gmail.com, pedro.faggion@gmail.com,kngveiga@gmail.com, cnadal@ufpr.br, \\ asoares@copel.com, wanderdacruz@gmail.com, isabella.figueira@lactec.org.br
}

\begin{abstract}
Resumo
A gravimetria consiste no conjunto de métodos e técnicas empregadas na medida do campo da gravidade terrestre, com o objetivo de mapear as variações de densidade da superfície da Terra ou de materiais nela contidos, de modo a subsidiar estudos em várias áreas das Geociências. A avaliação da anomalia da gravidade na região do barramento da Usina Hidrelétrica de Mauá se dá em função desse barramento ter sido construído no contexto geológico de rochas ígneas, na forma de soleiras de diabásio, da Formação Serra Geral, sobre rochas sedimentares, da Bacia do Paraná. Esta região apresenta uma forte estruturação caracterizada por fraturas, falhas transcorrentes e normais. Estas condições conferem cuidados especiais à obra, por parte do projetista, em função de sua menor resistência mecânica, menor densidade, maior porosidade e suscetibilidade a processos de degradação quando expostas ao intemperismo ou à ação hidráulica. Os resultados do processamento de dados gravimétricos realizados nesta pesquisa evidenciam sinais de que a variação do nível de água no reservatório causa variações no comportamento da anomalia residual. Evidencia também a presença de possíveis falhas na região da ombreira esquerda da barragem caracterizada por variação abrupta da anomalia residual, o que estaria de acordo com o mapeamento geológico realizado anteriormente e que identificou a presença de um maciço rochoso constituído de diabásio, que está segmentado por falhas normais e transcorrentes.
\end{abstract}

Palavras-chave: Anomalias da Gravidade; Monitoramento; Concreto Compactado a Rolo

\begin{abstract}
The gravimetry consists in the set of methods and techniques employed in the measurement of the terrestrial gravity field, aiming at mapping out the density variations of the earth surface or of materials contained therein, in order to subsidize studies in several areas of Geosciences. The evaluation of the gravity anomaly in the region of the barrier of the Hydroelectric Plant of Mauá is due to fact that the barrier has been built in geological context of igneous rocks, in the form of diabase sills, of the Serra Geral formation, on sedimentary rocks of Paraná Basin. This region has a strong structure characterized by fractures, elapsed and normal faults. These conditions give special care to the work, by the designer, on the basis of their lower mechanical resistance, lower density, higher porosity and susceptibility to processes of degradation when exposed to weathering or the hydraulic action. The results of the gravimetric data processing performed in this study show signs that the variation of water level in the reservoir causes variations in the behaviour of the residual anomaly. It also shows the presence of possible faults in the region of the left bank of the dam characterized by abrupt variation of residual anomaly, what would be in accordance with the geological mapping previously performed that identified the presence of a massive rocky formation composed of rock, which is segmented by elapsed and normal faults.
\end{abstract}

Keywords: Gravity anomalies; Monitoring; Concrete compacted by roll 


\section{Introdução}

As anomalias da gravidade, obtidas a partir de reduções do valor da gravidade observado, são ferramentas comuns ao geodesista, ao geólogo e ao geofísico, entre outros profissionais ligados as Geociências. Vanicek e Krakiwski (1982) afirmaram que é difícil distinguir onde é que a geofísica termina e onde é que a Geodésia inicia. Esta ideia foi ressaltada por Gemael (2012) ao afirmar que a Geodésia estabelece um vínculo recíproco com a Geofísica e a Geodinâmica. Para a Geofísica, a gravimetria atua na pesquisa de recursos naturais e, para a Geodésia, na determinação das ondulações do geoide e do desvio da vertical. Em primeira aproximação pode-se dizer que a Geodésia se preocupa com a Gravimetria em escala global, enquanto a Geofísica está mais interessada em determinações regionais e/ou locais. Mas as determinações gravimétricas feitas por uma servem a ambas (GEMAEL, 2012). A Geodésia, através de suas técnicas de medição, que se caracterizam pela precisão milimétrica e/ou submilimétrica, tem motivado pesquisas intensas na área de Geodésia e Levantamentos Geodésicos da Universidade Federal do Paraná. Estas pesquisas têm sido desenvolvidas nas barragens das usinas hidrelétricas Bento Munhoz da Rocha (Foz do Areia), Governador Ney Braga (Segredo), Governador José Richa (Salto Caxias), Gemael e Faggion (1995) e mais recentemente na barragem da Usina Hidrelétrica de Mauá, no rio Tibagi (MUGUIO, et al. 2015).

As regiões onde são instaladas as barragens principalmente com a formação de grandes lagos são potencialmente sismogênicas e o estudo da subsidência do solo em suas vizinhanças, interessa, sobremodo, ao geofísico. A Geodésia, dada a elevada precisão de seus métodos de mensuração, tem condições de detectar tal subsidência e assim contribuir na elucidação do mecanismo que desencadeia a sismicidade (GEMAEL, 2012). O controle e segurança de uma barragem encontram-se na análise de seu comportamento estrutural, com base no monitoramento de um conjunto de variáveis que descrevem as relações entre as ações e as respostas estruturais correspondentes, tendo em consideração as propriedades dos materiais utilizados na construção (CASACA e HENRIQUES, 2002). Estas barragens podem ser construídas em concreto, terra e enrocamento (COSTA, 2012).

A barragem da Usina Hidrelétrica de Mauá, que é objeto deste estudo foi construída com a tecnologia CCR - Concreto Compactado a Rolo. O CCR possui os mesmos materiais que o concreto convencional, porém com dosagens diferentes de cimento, que conferem uma consistência seca, o qual é espalhado e compactado com equipamentos tradicionalmente empregados na pavimentação rodoviária (PCA, 1987). A técnica do CCR permite que haja redução de riscos de fissuração térmica e de reação álcali-agregado, em relação ao concreto convencional, devido principalmente ao baixo consumo de cimento (LACERDA, et al. 2006).

Segundo Figueira, et. al. (2015), a barragem da Usina Hidrelétrica de Mauá é uma estrutura de gravidade, construída no contexto geológico de rochas ígneas, na forma de soleiras de diabásio, da Formação Serra Geral, sobre rochas sedimentares, da Bacia do Paraná. Esta região apresenta uma forte estruturação que pode ser observada localmente ou evidenciadas em imagens aéreas de satélites, caracterizada por fraturas, falhas transcorrentes e normais. Estas condições conferem cuidados especiais à obra, por parte do projetista, em função de sua menor resistência mecânica, menor densidade, maior porosidade e suscetibilidade a processos de degradação quando expostas ao intemperismo ou à ação hidráulica (DUARTE, et al. 2010).

Batista, et al. (2003), afirmam que o concreto é um material heterogêneo e sua porosidade é uma das propriedades que contribui para o envelhecimento e deterioração das barragens de concreto. Para garantir estanqueidade ao longo dos anos são utilizadas soluções em concreto convencional pré-moldado e mantas poliméricas diversas (WENDLER, 2010). Apesar disso, a face de montante da barragem está em contato contínuo com a água, onde os efeitos de variação de temperatura, devido ao calor de hidratação do cimento e de movimentação higrotérmica passam a ser significativos, podendo 
ocasionar fissuras. Em consequência destas fissuras, da característica porosa do CCR, do fraturamento do maciço rochoso da fundação e de sua constituição litológica, admite-se a possibilidade de infiltração da água, que, gradualmente poderá provocar variações na densidade do concreto. Estas variações podem ser equiparadas às variações do campo gravitacional da Terra causadas pelas diferenças de densidade das rochas em subsuperfície (KEAREY, et al. 2009) ou pelas alterações no volume de água armazenada nos reservatórios hidrogeológicos (UTLA e PORWAL, 2013).

Kearey et al. (2009) afirmam que massas anômalas causam uma perturbação localizada no campo gravitacional, conhecida como anomalia da gravidade. É neste contexto que se desenvolveu a presente pesquisa com o objetivo de avaliar as variações e o comportamento das anomalias da gravidade na região do barramento da Usina Hidrelétrica de Mauá.

\section{Metodologia}

\subsection{Localização da Usina Hidroelétricas Mauá}

A barragem da Usina Hidrelétrica de Mauá localiza-se no rio Tibagi, entre os municípios de Telêmaco Borba e Ortigueira (Figura 1). É o primeiro aproveitamento de médio porte a ser implantado no contexto geológico de rochas sedimentares do Segundo Planalto Paranaense, onde também ocorrem disseminadas no maciço, intrusões de rochas ígneas na forma de soleiras e diques de diabásio.

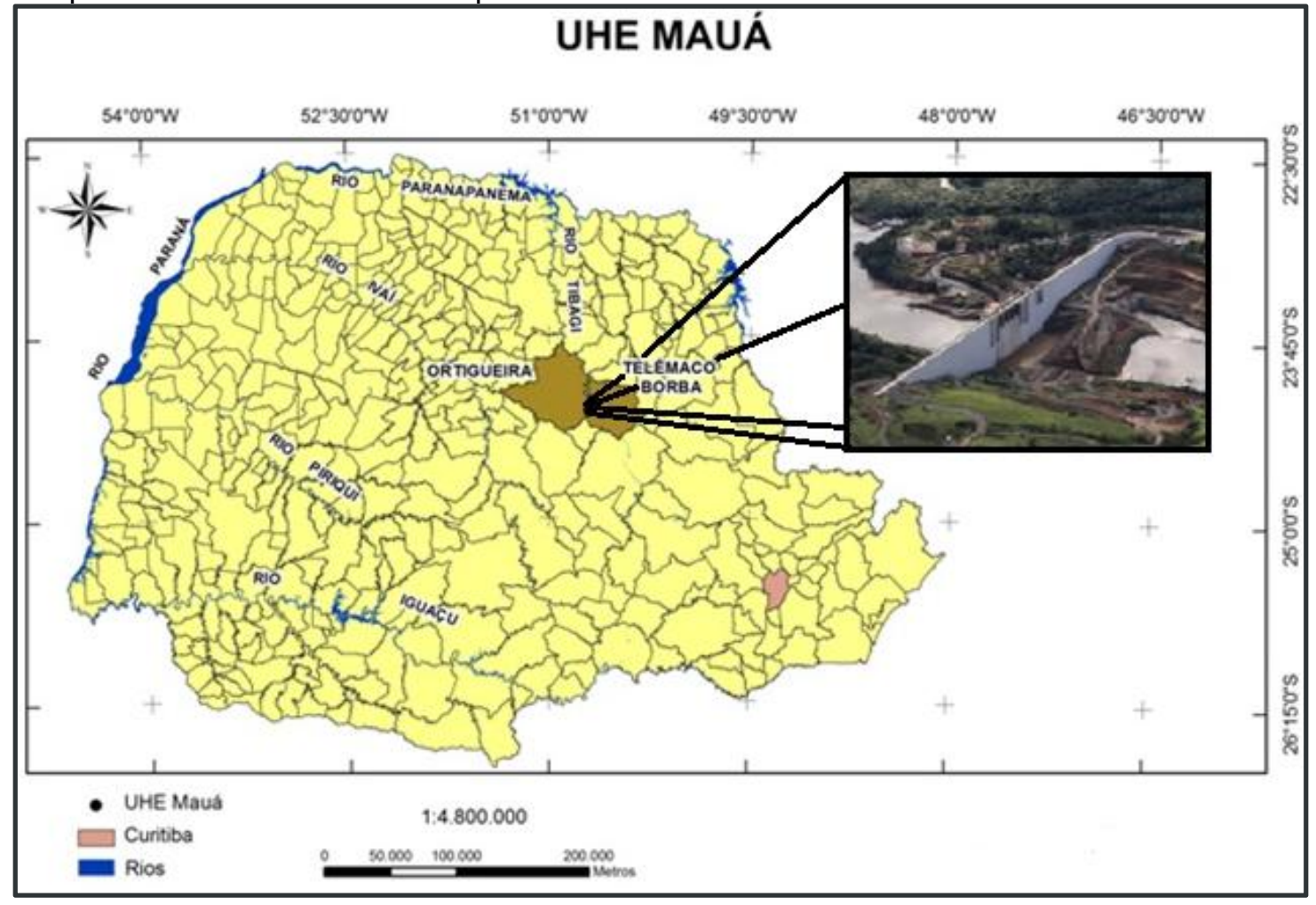

Figura 1 - Localização da Usina Hidrelétrica de Mauá. Fonte: (Siguel, 2013)

\subsection{Caracterização geológica e estrutural da região da barragem}

Inicialmente realizou-se o mapeamento das principais direções estruturais do relevo, por meio da análise em imagens aéreas e orbitais, que são representadas pelos alinhamentos das cristas e vales, extraídos principalmente de modelos tridimensionais de terreno (SRTM - Shuttle Radar Topography Mission). Uma vez identificadas as principais feições de relevo, foram realizados mapeamentos geológicos e estruturais no maciço rochoso da região da barragem (figura 2 ), nos quais 
foi identificada uma soleira de diabásio intrudida em folhelhos e siltitos da Formação Irati (FIGUEIRA, et al. 2015).

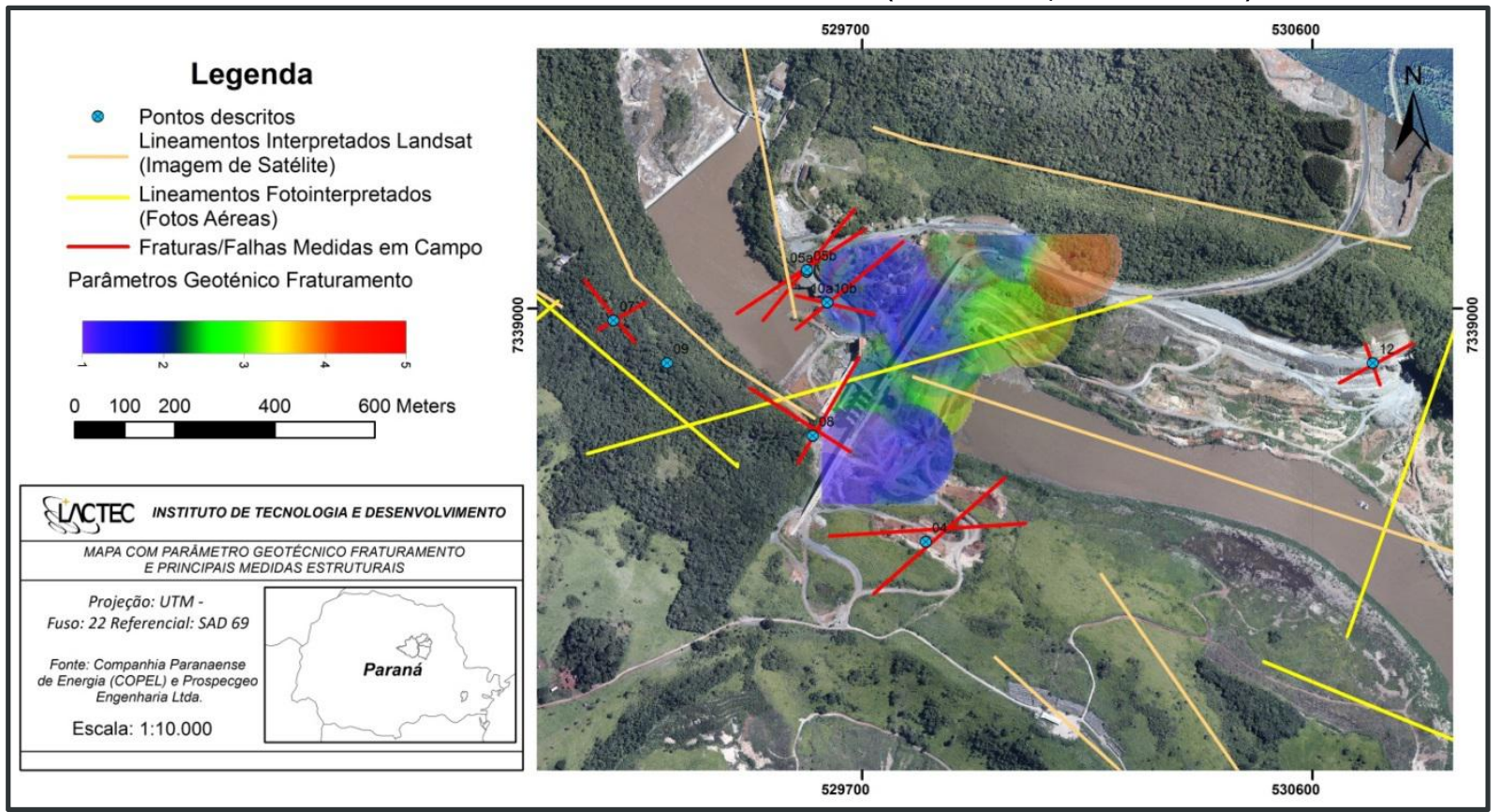

Figura 2 - Caracterização estrutural da região da barragem da UHE de Mauá. Fonte: (Figueira, et. al. 2015).

\subsection{Implantação da rede gravimétrica}

Para viabilizar os levantamentos gravimétricos na barragem, inicialmente foi realizado o transporte do valor da gravidade da estação absoluta (de 1 ạ ordem), materializada no Laboratório de Instrumentação Geodésica - LAIG da UFPR (figura 3), para a estação gravimétrica de referência de $\mathrm{RN}-5$ (figura 4 ) implantado próximo à barragem e fora da zona de influência do reservatório. O transporte de base foi feito através de um circuito fechado, para o controle dos erros, e garantindo um resultado compatível com a precisão da estação de $1^{a}$ ordem utilizada como referência. O valor da aceleração da gravidade na estação LAIG é 978760,377 mGal e pertence a rede gravimétrica brasileira de primeira ordem, cujo valor foi determinado por método absoluto.

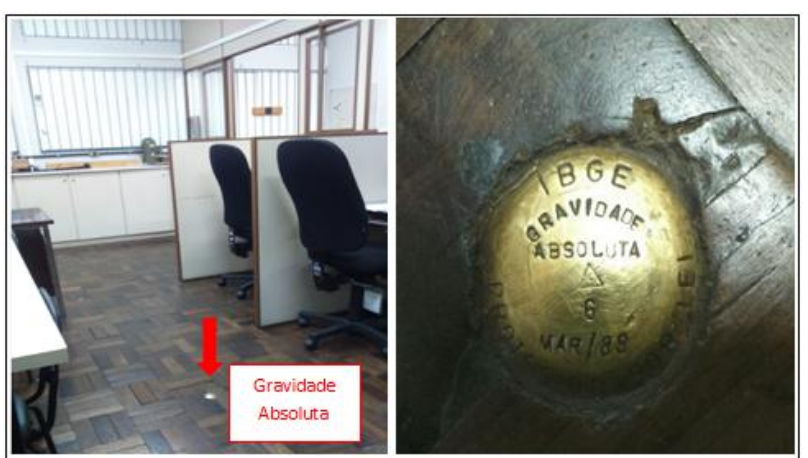

Figura 3 - Estação gravimétrica absoluta materializada no LAIG da UFPR.

Este procedimento é sustentado por Torge (1991), ao afirmar que uma rede deve conter pelo menos uma medida de gravidade absoluta implantada por um marco estabelecido num local estável (estabilidade geológica, hidrológica e de pouca sismicidade) e permanente (instituições científicas). Gemael (2012), afirmou que para assegurar o valor de referência da gravidade, cada país deve estabelecer a sua "rede nacional" integrada por estações de 1 a geograficamente bem distribuídas e amarradas ao International Gravity Standardization Net 1971 (IGSN-71) para facilitar a tarefa dos geodesistas, geólogos e 
geofísicos que pretendam efetuar densificações gravimétricas.

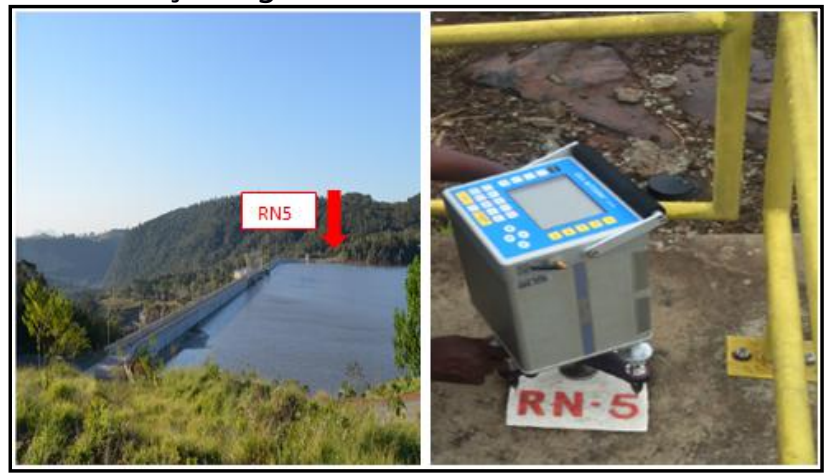

Figura 4 - Estação gravimétrica de referência RN-5.

A RN-5 acima descrita foi adotada como marco de referência para os levantamentos gravimétricos na região da barragem, e o valor da aceleração da gravidade obtido a partir do transporte é de $\mathrm{g}=978755,292$ mGal.

A densificação gravimétrica na região da barragem utilizou o conceito de circuito fechado, sendo a partida e a chegada situadas na RN-5. Neste tipo de circuito há a necessidade de cálculo da deriva instrumental, que ocorre devido a mudanças no comportamento do sistema elástico do gravímetro, de modo que as leituras executadas numa mesma estação, em diferentes horários, não coincidam (KNÖDEL, 2007; GEMAEL, 2012). O circuito implantado é composto por 35 estações, das quais, 33 estão situadas sobre a barragem, conforme a figura 5.

\subsection{Espaçamento entre as estações}

Os levantamentos gravimétricos, além de globais ou regionais, também são realizados em escala local ou de detalhe, com espaçamento entre as estações de 100 metros, ou menor, que apesar de não contribuir substancialmente para a cobertura regional, são utilizados para investigações especializadas, tais como nos levantamentos para a exploração de petróleo, localização de domos de sal, exploração mineral, cubagem de jazidas, localização de vazios, como cavidades naturais ou antrópicas (PATERSON e REEVES, 1985). Kearey et. al. (2009), afirmam que o espaçamento das estações de uma rede com a finalidade de se executar um levantamento gravimétrico pode variar de uns poucos metros, no caso de levantamentos geotécnicos ou de detalhe para mineração, a vários quilômetros em levantamentos regionais. No projeto de levantamento da Usina Hidrelétrica de Mauá adotou-se um intervalo de amostragem de $25 \mathrm{~m}$ tendo por fundamento a possibilidade de uma rápida variação do campo da gravidade resultante de variações na densidade do concreto.

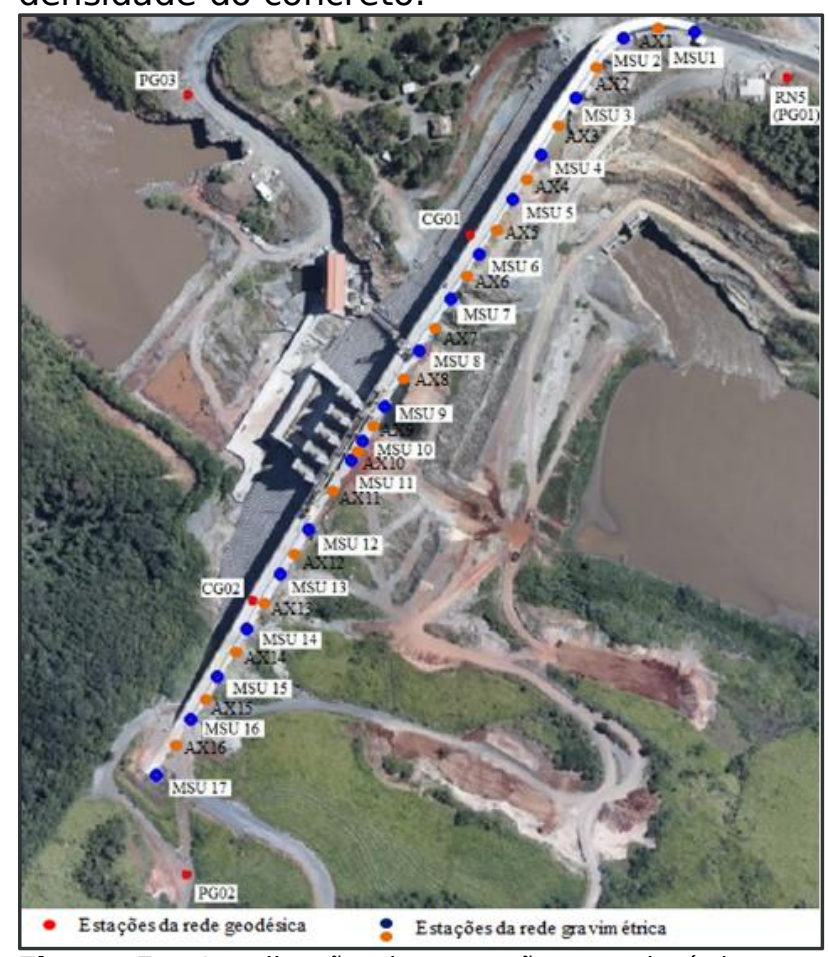

Figura 5 - Localização das estações gravimétricas na barragem da UHE de Mauá.

\subsection{Medições gravimétricas}

Segundo Torge (1989), a magnitude do vetor gravidade é obtida através de medições absolutas ou relativas. As medições absolutas resultam no valor de $\mathrm{g}$ para uma estação, através de um pêndulo ou da queda livre de uma massa, enquanto as medições relativas devem ser realizadas em pelo menos duas estações, obtendo-se a diferença de aceleração da gravidade $\Delta \mathrm{g}$. Antes dos gravímetros, as medições relativas também eram realizadas através de pêndulos, que devido a sua sensibilidade exigiam um operador especializado, cujo rendimento máximo era de uma estação por dia (GEMAEL, 2012).

Modernamente as medições absolutas são realizadas por gravímetros absolutos, que permitem registrar, pequenos intervalos de 
tempo e variações de distância ao longo da queda de uma massa. Este processo foi utilizado na obtenção da aceleração da gravidade na estação LAIG da UFPR.

O levantamento de campo foi realizado com o gravímetro relativo digital SCINTREX CG-5 pertencente a UFPR. Inicialmente, após registrar os parâmetros que caracterizam o levantamento no sistema computacional do gravímetro, foram estipulados cerca de 5 minutos para garantir a estabilidade de seu sistema elástico. Para garantir a precisão desejada foram realizadas 360 leituras (seis a cada segundo) em cada estação. Durante as medições foi acoplado ao gravímetro um receptor GPS (Global Positioning System) para a obtenção das coordenadas geodésicas das estações, usadas no cálculo das correções de rotina e na determinação do valor da gravidade normal, para posterior cálculo das anomalias da gravidade.

\subsection{Determinação da gravidade normal}

A Fórmula Internacional da Gravidade, de 1980, deduzida do potencial normal é a base para o cálculo do valor da aceleração da gravidade normal na superfície do elipsóide de referência (MORITZ, 1984).

$\mathrm{y}_{1980}=978032,67715\left(1+0,005301 \sin ^{2} \varnothing-0,0000058 \sin ^{2} \varnothing\right.$ (1)

Como se pode observar, esta equação é expressa como função da latitude geodésica, uma das componentes das coordenadas geodésicas de cada estação, necessária para o cálculo da gravidade teórica sobre o elipsóide (NABIGHIAN et. al. 2005). O valor da aceleração da gravidade em cada estação varia também com a altitude ortométrica, sendo esta mais significativa. Estes aspectos fazem com que haja necessidade de associar as redes gravimétrica e geodésica tridimensional para a determinação das coordenadas geodésicas de alta precisão das estações ocupadas durante o levantamento gravimétrico.

No caso da barragem da Usina Hidrelétrica de Mauá, as coordenadas geodésicas ( $\lambda$ e h) das estações gravimétricas foram determinadas com precisão compatível à recomendada para posicionamentos de primeira ordem.

\subsection{Cálculo da anomalia Bouguer}

Para o cálculo da anomalia Bouguer foram realizadas medições gravimétricas em todas as estações do circuito estabelecido, cujos valores foram anteriormente corrigidos do efeito de maré terrestre e deriva instrumental (estática e dinâmica) (MILSOM, 2003). A deriva estática está associada à deformação da mola e grandes flutuações de temperatura e pressão, enquanto que a deriva dinâmica está associada a choques, pequenas variações de temperatura e outros fatores. Além destas correções, as medições gravimétricas foram comparadas com o valor da gravidade normal sobre a superfície do elipsóide. Para tal foram realizadas outras reduções, tais como, latitude, Ar Livre e Bouguer (HOFMANN e MORITZ, 2005; NABIGHIAN et al. 2005).

$\Delta \mathrm{g}_{\mathrm{b}}=\mathrm{g}+0,1967 \mathrm{H}+\mathrm{C}_{\mathrm{t}}-\mathrm{Cb}_{\mathrm{b}}-\mathrm{Y}$

Onde:

$\Delta \mathrm{g}_{\mathrm{b}}$ - Anomalia Bouguer (mGal);

g - Valor da gravidade obtido após correções e reduções;

$\mathrm{H}$ - Altitude Ortométrica em metros;

y - Gravidade normal determinado para cada ponto observado através da Fórmula de Internacional, em função da latitude;

$\mathrm{C}_{\mathrm{t}}$ - Correção de Terreno;

$\mathrm{C}_{b}$ - Correção Bouguer.

\section{Discussão de resultados}

Para avaliar o comportamento da anomalia da gravidade na região do barramento foram traçados os perfis das anomalias residuais (figura 6) referentes aos meses de Setembro/14, Dezembro/14, Março/15 e Setembro/15.

Estes perfis de anomalias residuais foram obtidos a partir da subtração entre a anomalia Bouguer e a anomalia regional, esta definida pelo polinômio de 6o grau. Anomalia regional é a anomalia que possui comprimento de onda maior do que o gerado pelo corpo de interesse e é determinado por uma superfície polinomial que melhor representa o comportamento geral dos dados. Lowrie (2007) afirma que várias técnicas têm sido aplicadas para a decomposição de uma 
anomalia de gravidade. A separação regionalresidual é um procedimento importante na interpretação de mapas gravimétricos. A análise pode ser baseada em perfis selecionados sobre algumas estruturas, ou pode envolver a distribuição bidimensional da anomalia em um mapa de gravidade.

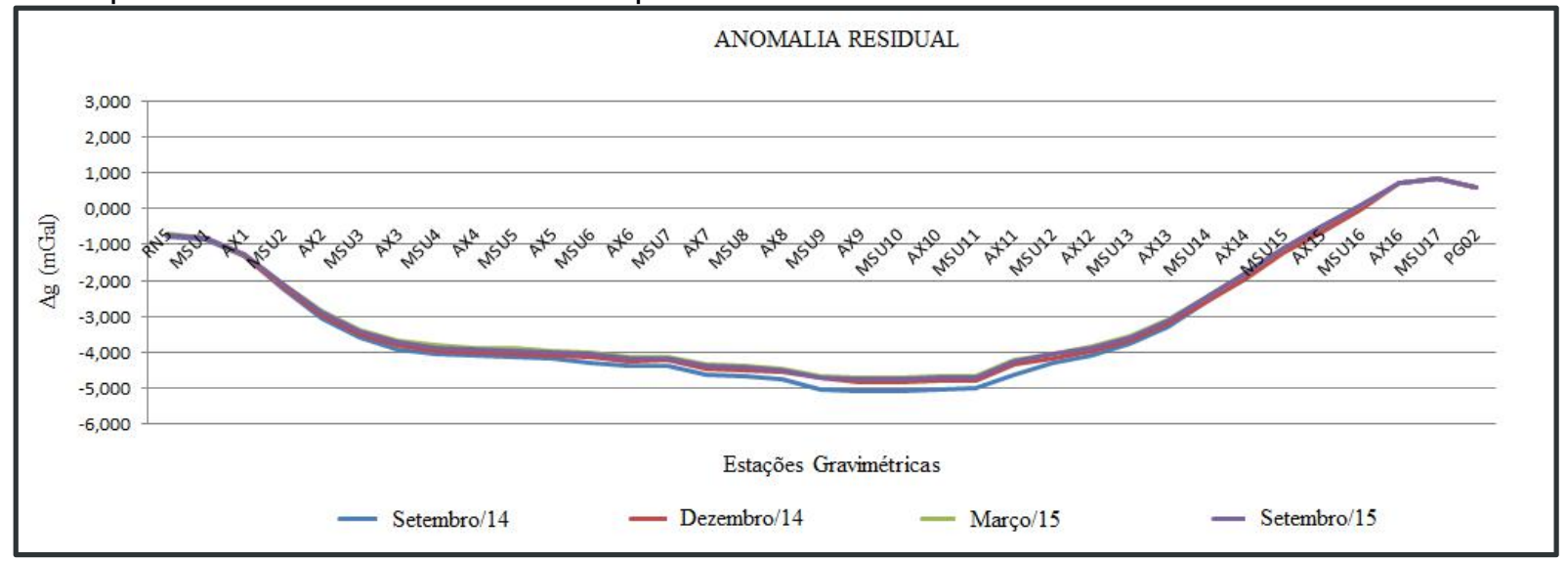

Figura 6 - Perfis da anomalia residual (vide localização das estações gravimétrcas na figura 5).

Ao longo dos perfis da anomalia residual observam-se sinais gravimétricos de interesse, nomeadamente, baixo gravimétrico entre AX1 e MSU16 e alto gravimétrico entre as estações AX16 e MSU17. O baixo gravimétrico pode estar associado à massa de água represada no reservatório. Porém, entre as estações MSU9 e MSU11, este se apresenta com maior expressão, fato que pode estar relacionado ao maior acúmulo de água no reservatório, ou as rochas sedimentares da Formação Rio Bonito constituídas predominantemente por arenitos e siltitos. A densidade média dos arenitos e siltitos $(2,5 \mathrm{~g} / \mathrm{cm} 3)$ são menores que às rochas adjacentes da Formação Serra Geral $(2,78 \mathrm{~g} / \mathrm{cm} 3)$, representadas por diques e soleiras de diabásio. O alto gravimétrico pode estar associado às estruturas geológicas relacionadas ao soerguimento do Arco de Ponta Grossa (figura 7) que são pervasivas em toda a área de estudo e conferem ao relevo feições morfoestruturais peculiares derivadas de diques e soleiras de diabásio, que compõem o maciço sob a UHE de Mauá.

Castro et al. (2008) ao estudarem o Gráben de Paranaguá (PR) observaram que o alto gravimétrico orientado segundo NW-SE corresponde ao trend de maior concentração de diques de diabásio relacionada ao Arco de Ponta Grossa, região onde foi implantada a barragem da UHE de Mauá (figura7).

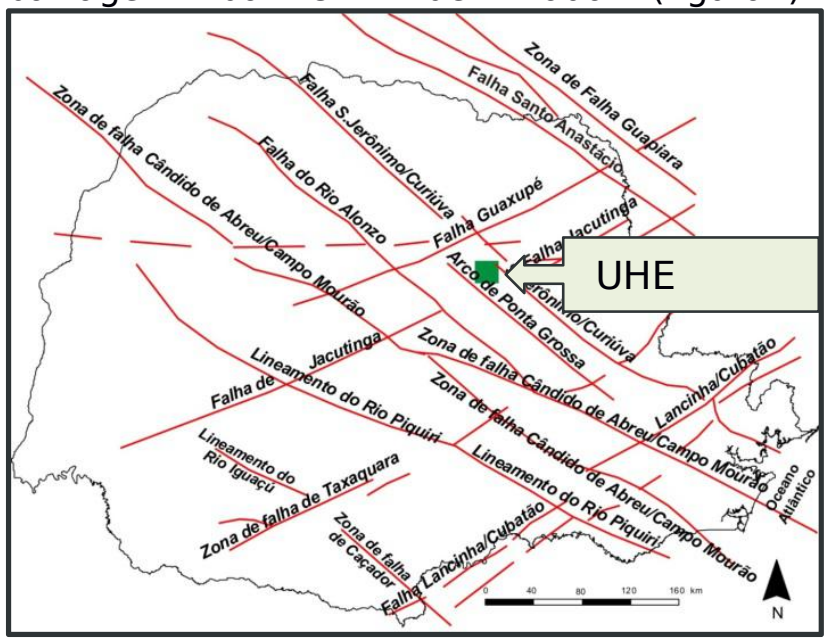

Figura 7 - Arcabouço estrutural do Estado do Paraná com os principais lineamentos. Fonte: Modificado de Zalan et. al., (1990)

É desejável que a diferença entre os perfis gravimétricos residuais, em relação à uma época de referência, se mantenha nula, o que representaria a não evolução da anomalia. Porém, tais variações são esperadas em decorrência, principalmente, de alterações no volume de água armazenada nos reservatórios hidrogeológicos. A partir dos perfis da anomalia residual foram traçados os perfis de suas variações ao longo do tempo (figura 8). Estas variações foram calculadas pelas diferenças dos perfis da anomalia residual de cada época, tomando a época mais antiga (Setembro/14) como referência. 
Os perfis representados na figura 8 descrevem o comportamento da anomalia residual e permitem identificar possíveis falhas através de variações abruptas. Cabe salientar que na época de referência citada (Setembro 2014), o reservatório já estava preenchido.

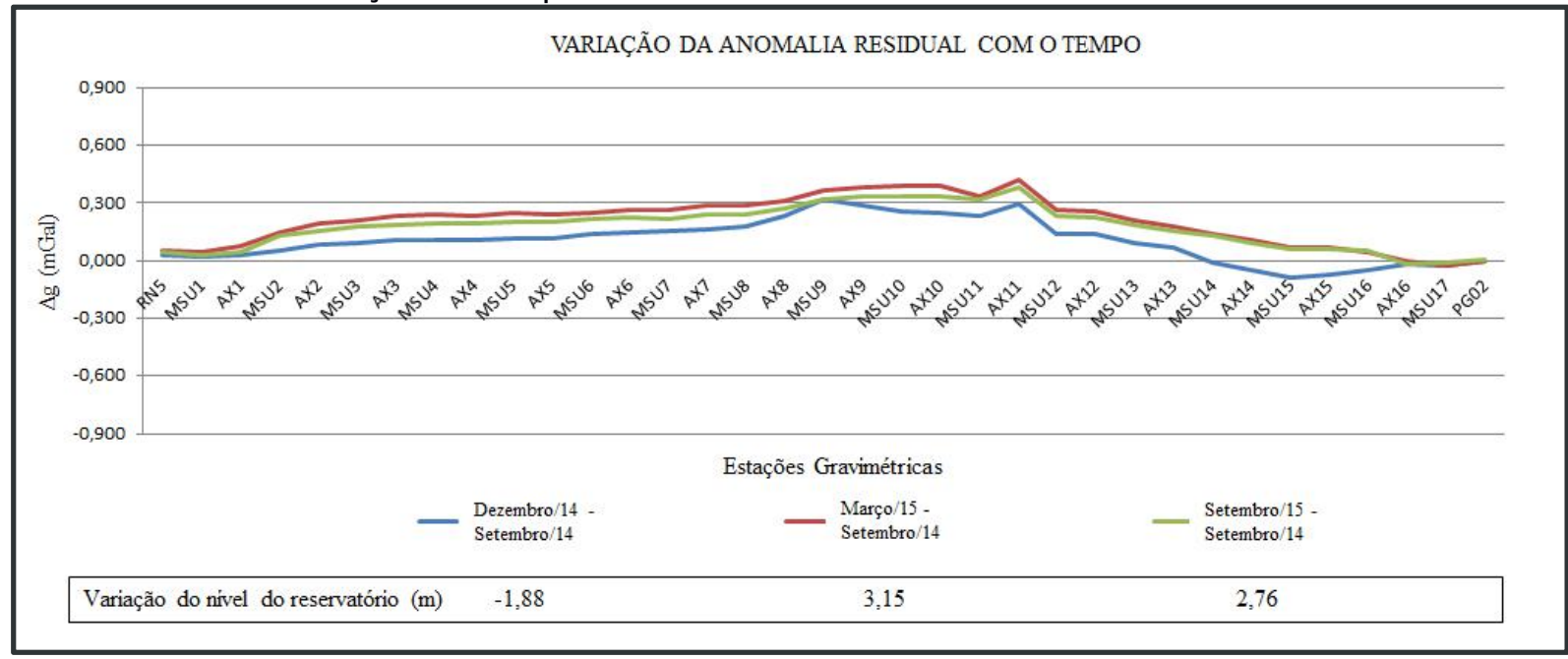

Figura 8 - Perfis de variação da anomalia residual adotando como referência Setembro/14.

Para o período em análise pode-se afirmar, observando a figura 8, que a amplitude da variação da anomalia residual é cerca de $0,400 \mathrm{mGal}$.

Entre setembro e dezembro de 2014 o nível do reservatório baixou $1,88 \mathrm{~m}$ (simbolizado pelo sinal negativo na figura 8) e ocasionou uma variação máxima de 0,319 mGal na anomalia residual. Entre setembro de 2014 e março de 2015, o nível do reservatório aumentou $3,15 \mathrm{~m}$ ocasionando variação máxima da anomalia residual igual a 0,418 $\mathrm{mGal}$. A variação entre os máximos $(0,099$ mGal) é significativa e correspondente a uma variação de gravidade em pontos separados por uma altura de $32 \mathrm{~cm}$, utilizando-se o valor médio do gradiente vertical da gravidade igual a 0,3086 $\mathrm{mGal} / \mathrm{m}$. Neste caso, como era de se esperar, há uma correlação da gravidade com a variação da altura do reservatório.

Observa-se também na figura 8 , que, entre as estações AX11 e MSU12 existe uma variação abrupta da anomalia residual, que pode estar correlacionada com um contato vertical entre as rochas sedimentares e o dique de diabásio. $\mathrm{Na}$ imagem da figura 2, representado em vermelho, é possível verificar fraturas/falhas identificadas no campo.

\section{Considerações finais}

A variação do nível do reservatório influencia o comportamento da anomalia residual. Assim, a diminuição da anomalia residual está relacionada com massa atrativa menor decorrente do rebaixamento do nível de água e da profundidade da lâmina d'água.

Os resultados gravimétricos também sugerem a influência da geologia na resposta gravimétrica. Desta forma, falhas e fraturas identificadas pelo mapeamento geológico na região da ombreira esquerda da barragem, entre as estações AX11 e MSU12 foram responsáveis pela variação abrupta da anomalia residual apresentada na figura 8.

Levantamentos complementares são sugeridos, como medidas das componentes horizontal e vertical da gravidade induzida pela variação do volume do reservatório, além da aquisição de dados gravimétricos nas galerias de inspeção para averiguar suas relações com as leituras dos piezômetros e a variação do volume do reservatório.

\section{Agradecimentos}

Agradecemos o apoio dado pela Copel Geração S/A e pelo projeto PD-64910227/2011-2015 Aneel, no financiamento das campanhas para a coleta dos dados e ao Prof. 
Dr. Donizeti Antônio Giusti pelo auxilio na

interpretação dos resultados.

\section{Referências bibliográficas}

BATISTA, E. L., GRAÇA, N. G., FARIAS, L. A., Bittencourt, R. M. 2003. Porosity studies for roller compactec concrete $=$ roller compactec concrete dams, - Fourth International Symposium on Roller Compacted Concrete (Rcc) Dams. MADRID.

CASACA, J., HENRIQUES, M. 2002. The Geodetic Surveying Methods in Monitoring of Large Dams in Portugal. FIG XXII International congress. Wahington D.C. USA.

CASTRO, L. G., FERREIRA, F. J. F., ANGULO, R. J. 2008. Modelo Gravimétrico-Magnético do Gráben de Paranaguá - PR, Brasil. Revista Brasileira de Geofísica, 26(3): 273-292.

COSTA, W. D. 2012. Geologia de Barragens. São Paulo: Oficina de textos.

DUARTE, J. M. G., MORAES R. B., OLIVEIRA, C. A., CARDOSO, R. M. 2010. Alguns Aspectos Geotécnicos Peculiares do Projeto da UHE Mauá. Geosul.

FIGUEIRA, I. F. R., RIVAS, R. S. Z., SOARES, M. A. 2015. Geological mapping and foundation geomechanics characterization for the identification places for detailed monitoring in plants maintenance. In: Second International Dam World Conference. Proceedings. LISBOA: LNEC. v. 01. p. 669-676.

GEMAEL, C. 2012. Introdução à Geodésia Física. Curitiba, Editora da UFPR.

GEMAEL, C., FAGGION, P. 1995. Auscultação geodésica na região da Hidrelétrica Segredo (II). 40 Congresso internacional da SBGf. Rio de Janeiro.

HOFMANN, B., MORITZ, H. 2005. Physical Geodesy. Springer Wien New York.

KNODEL, K. LANGE, G. VOIGT, H. J. 2007. Environmental Geology. Handbook of Field Methods and Case Studies.

LACERDA, D., CABRAL, D., MATHIAS, H., LEMOS, M., RIVELINO, R. 2006. Fatores que determinaram o CCR - Concreto compactado com rolo como material para o projeto estrutural da Barragem do AHE Peixe Angelical. Trabalho final de graduação, Universidade católica de Goiás.

LOWRIE, W. 2007. Fundamentals of Geophysics. Cambridge University Press, New York.

MILSOM, J. 2003. Field Geophysics. The Geological Field Guide Series. Wiley, 3a edição.

MORITZ, H. 1984. Geodetic Reference System 1980. Bulletin Geódésique, Vol. 58, pp.388-398.

MUGUIO, M. R.; FAGGION, P. L.; VEIGA, L. A. K. ; NADAL, C. A.; CRUZ, W.; SOARES, M. A.; FIGUEIRA, I. F. R.. Implementation and analysis of GNSS station for continuous monitoring of the hydropower plant of Mauá. Espaço Energia, v. 10, p. 56-61, 2015.

NABIGHIAN, M. N., ANDER, M. E., GRAUCH, V. J. S., HANSEN, R. O., LAFEHR, T. R., LI, Y., PEARSON, W. C., PEIRCE, J. W., PHILLIPS, J. D., RUDER, M. E. 2005. Historical Development of the Gravity Method in Exploration. Society of Exploration Geophysicists.

KEAREY, P., BROOKS, M., IAN, H. 2009. Geofísica de Exploração. Michael Brooks, lan Hill; Tradução Maria Cristina Moreira Coelho. São Paulo: Oficina de Textos.
PATERSON, N. R. \& REEVES, C. V. 1985. Applications of Gravity and Magnetic Surveys. Society of Exploration Geophysicists.

PCA. 1987. Bonding Roller Compacted Concrete Layers. Concrete Information. Skokie, USA: Portland Cement Association.

SIGUEL, A. R. 2013. Monitoramento da Barragem da Usina Hidrelétrica de Mauá Utilizando Irradiação Tridimensional. Dissertação de Mestrado. PósGraduação em Ciências Geodésicas, Departamento de Geomática, Universidade Federal do Paraná. 171p.

TORGE, W. 1989. Gravimetry. Walter de Gruyter: Berlin and New Work. 465pp.

TORGE, W. 1991. Geodesy. Walter de Gruyter: Berlin and New Work.

UTLA, K. \& PORWAL N. 2013. Interpretation of Satellite Gravity Anomalies over Himachal Pradesh, India in Relevance to Groundwater Storage Fluctuations. International Journal of Remote Sensing \& Geoscience.

VANICEK, P. \& KRAKIWSKI, E. 1928. Geodesy: the concepts. North Holland Publishing Co.

WENDLER, A. P. 2010. Estudo Experimental do Concreto Compactado a Rolo Enriquecido com Calda de Cimento para Face de Barragens de Concreto. Dissertação de Mestrado. Pós-Graduação em Construção Civil, Setor de Tecnologias, Universidade Federal do Paraná. 115p.

ZALÁN, P. V.; WOLF, S.; ASTOLFI, M. A. M.; VIEIRA, I. S.; CONCEIÇÃO, J. C. J.; APPI, V. T.; SANTOS NETO, E. V.; CERQUEIRA, J. R.; MARQUES, A. 1990. The Paraná Basin, Brazil. In: LEIGHTON, M. W.; KOLATA, D. R.; OLTZ, D. F.; EIDEL, J. J. (Ed.). Interior cratonic basins. Tulsa: American Association of Petroleum Geologists, p. 681-708.
Manuscrito ID 49105

Submetido em agosto de 2016 Aceito em dezembro de 2016 